\title{
Simple heat profiles and biogeochemical patterns for analysis the influence on soil microbial community of plastic-greenhouse and open field condition
}

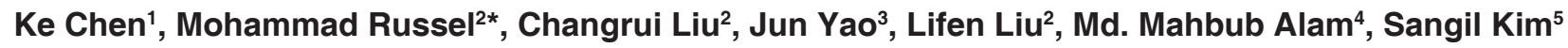 \\ ${ }^{1}$ College of Resources and Environmental Sciences, South-central University for nationalities, 182 Minyuan Road, Hongshan District, Wuhan \\ City, Hubei 430074, People's Republic of China, ${ }^{2}$ School of Food and Environment, Key laboratory of Industrial Ecology and Environmental \\ Engineering, Ministry of Education, Dalian University of Technology, Panjin 124221, P.R. China, ${ }^{3}$ School of Civil \& Environmental Engineering, \\ and National "International Cooperation Base on Environment and Energy", University of Science and Technology Beijing, 100083 Beijing, \\ P.R.China, ${ }^{4}$ Institute for Turbulence-Noise-Vibration Interaction and Control, Shenzhen Graduate School, Harbin Institute of Technology, \\ Shenzhen 518055, P.R. China, ${ }^{5}$ Departmentof Mechanical Engineering, Kangwon National University, 346 Jungang-ro, Samcheok 25913, \\ Republic of Korea
}

\section{A B S T R A C T}

The diversity of the soil microbial community is remarkably sensitive to different cropping techniques. To examine the effects of cultivation in a greenhouse on the soil microbial activity and diversity, we collected soil samples from vegetable crops continuously grown in a plastic greenhouse $(G)$ and an open field $(N)$. Heat profiling was obtained using microcalorimeter in the presence of different carbon sources. Power time curves were recorded after glucose and ammonium sulphate supplementation. The total heat release QT $\left(\mathrm{Jg}^{-1}\right)$, maximum heat

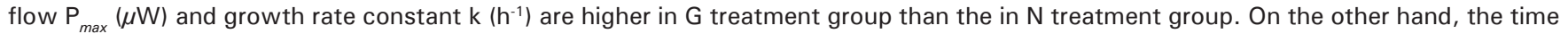
$\left(t_{\max }\right)$ to reach the peak heat flow is lower in $\mathrm{G}$ treatment group compared to $\mathrm{N}$ treatment group, as is cell specific heat rate $J_{Q / N}(\mathrm{~J}$ celli-1). Sample $\mathrm{G} 1$ has the highest $\mathrm{P}_{\max }(1246.07 \mu \mathrm{W})$ and the lowest $\mathrm{t}_{\max }(11.86 h)$; in contrast, sample N5 has the lowest $\mathrm{P}_{\max }(411.03 \mu \mathrm{W})$ and the highest $\mathrm{t}_{\max }(21.78 \mathrm{~h})$. The microbial community in the soil was estimated from phospholipid fatty acid (PLFA) biomarkers analysis and a viable count, followed by a subsequent determination of the physicochemical parameters. The total average PLFA concentration range is found as $129.76-142.54 \mathrm{nmol} \mathrm{g}^{-1}$. Both thermodynamics properties and PLFA concentration was are significantly greater in $\mathrm{G} 1, \mathrm{G} 2$ and G3 treatment than in the other two (N5 \& N6) management systems $(P<0.05)$. Combination of both thermodynamic and PLFA profiling determines that the microbial population is higher in the soil from the greenhouse fertilization than from the open field cultivation. This novel approach could be applicable to a better understanding of (i) the changes in the soil microbial community in green house and open field cultivation practices, and (ii) the relationship between physicochemical properties and soil microbial community's diversity. Moreover, this would be a notable technique for the decision maker to choose the potential cultivation method for sustainable green-food development program.

Keywords: Greenhouse cultivation; Soil microbial activity; PLFA; Urease activity; Thermodynamic properties

\section{INTRODUCTION}

While vegetable production in China only increased by $16.9 \%$ from 1995 to 2000 , a $79.5 \%$ increase occurred in 2005 (National Bureau of Statistics of China, 2006). This growth was attributed to a rapid economic development in China. During this period (1995-2005), some land devoted to cereal production was converted into plastic greenhouse (poly-tunnel) lands to cultivate vegetables (Li et al., 2009). By 2004, nearly 2.1 million hectares had been transformed into poly-tunnel lands, creating one of the largest greenhouse-based vegetable production systems in the world (Lin et al., 2010). Greenhouse production depends on high-yield varieties, intense cropping, high irrigation, and pesticide and fertilizer applications (Lin et al., 2010). The biocide residues in vegetables, soil salinization, soil nutrient depletion and excessive fertilizer used in greenhouse fertilization have become prominent issues in China. Generally, sustainable agriculture advocates a maximum crop yield with a minimal adverse impact on soil fertility. A fertile soil provides all of the essential nutrients for crop growth, supporting a diverse, active microbial community

\footnotetext{
${ }^{*}$ Corresponding author:

Mohammad Russel, School of Food and Environment, Key laboratory of Industrial Ecology and Environmental Engineering, Ministry of Education, Dalian University of Technology, Panjin 124221, P.R. China. E-mail: mrussel@dlut.edu.cn
} 
that efficiently decomposes plant matter and renders a good soil structure (Mader et al., 2002). The understanding of microbial processes in soil is crucial for a farming management system, particularly for farmers relying on organic materials for nutrient input. Soil microorganisms are ecologically beneficial because they participate in many critical processes, such as mineral compound cycling, organic matter decomposition, and various biophysical processes. Soil fertility and productivity, in particular, have received increasing attention (Nannipieri et al., 2003; Anna et al., 2015). Due to their capability to respond quickly to environmental changes, it has been postulated that microorganisms might have a function as efficient bio-indicators in a farming system (Gamalero et al., 2005). However, soil heterogeneity is a common phenomenon (Nuñez et al., 1994; Nuñez et al., 2006) that constitutes a highly complex, dynamic and continuous evolution system. Therefore, it is a social urge to understand the influence of greenhouse and open field cultivation systems on soil microbial community and diversity. Generally, studies on soil microorganisms have been limited only to specific groups of organisms or a particular metabolic process, which has motivated us to conduct further research (Barros and Feijóo, 2003).

The introduction of microcalorimetry in soil studies has enhanced the ability to estimate the total metabolic activity of the soil microbial community. Thus, the estimation of the total metabolic activity via microcalorimetry would be a novel approach to address the previously mentioned research gaps. Notably, the technique is simple, sensitive, and minimally disturbs the sample. Apart from loading the sample into the detecting unit, no additional operations are required into the reaction system (Barros et al., 1997; Critter et al., 2004a). In addition, heat signals can be continuously recorded for the same sample for a complete cycle of microbial growth and metabolic activity, which is not possible with other methods (Nuñez et al., 1994; Barros and Feijóo, 2003; Critter et al., 2004), because the acquisition of heat changes associated with all metabolic processes involved in a particular culture is continuous (Barros et al., 2012). Thus, the power-time curve obtained provides an appropriate characterization of the metabolic processes (Hashimoto and Takahashi, 1982; Tobias et al., 2016). Moreover, microcalorimetry can also provide key quantitative-activity indices, such as the microbial growth rate constant, heat evolution process, metabolic enthalpy change and microbial growth heat yield (Barros et al., 2006; Shying et al.,2016).

To clarify the microbial community structure in soil, phospholipids fatty acid (PLFA) analysis was a potential approach. It is well-known that phospholipids fatty acids are the key component of all the microbe's membrane, and their fatty acid ester-linked side chains and their polarity will vary from eukaryotes and prokaryotes (Ge et al., 2013; Tobias et al., 2016). Therefore, to overcome the selective problems in microbial culture techniques, the PLFA analysis was widely used to determine the soil microbial community (Dong et al., 2014).

Although the use of calorimetric methods in microbial ecological studies has recently increased, thermodynamic data on various microorganisms in agricultural soil environments are still scarce (Wu et al., 2011; Tobias et al., 2016).

Soil samples from Huazhong Agriculture University, Wuhan, P.R. China, which is a humid subtropical city in the centre of China, were used in this study. The aim of this study is to develop a novel approach to investigate the changes of the soil microbial community in green house and open field cultivation practices and the relationship between physicochemical properties and soil microbial community's diversity. To the best of our knowledge, a few researchers have used the combination of microcalorimetry techniques to quantify and characterize the microbial community diversity structure on green house and open cultivation systems. To further verify the calorimetric data analysis to quantify the microbial community structure, we have used both PLFA analysis and micro-calorimetric methods. Preliminarily, we studied the properties of the soil samples to clarify the differences between cultivation in a plastic greenhouse and an open field cropping system. These methods could provide information to allow a better understanding of the microbial ecology under these different management systems and selection of appropriate management practices that will improve soil function and quality. Moreover, this would be the significant techniques for the decision maker to choose the potential cultivation method for sustainable green food development program.

\section{MATERIALS AND METHODS}

\section{Soil sampling and climate characteristics}

Soil samples were collected from plastic greenhouses at Huazhong Agriculture University $\left(113^{\circ} 41^{\prime-1} 15^{\circ} 05^{\prime} \mathrm{E}\right.$, $29^{\circ} 58^{\prime}-31^{\circ} 22^{\prime} \mathrm{N}$.), Wuhan, P.R. China, which is located at the confluence of the Yangtze and Hanshui rivers at the center of Hubei Province. Wuhan belongs to subtropical humid monsoon climate. According to the meteorological statistics, annual temperature is $15.8^{\circ}-17.5^{\circ} \mathrm{C}$, annual frost-free period lasts 211 to 272 days and annual sunlight duration is 1810 to 2100 hours. The annual precipitation and evaporation are $1269 \mathrm{~mm}$ and $269.9 \mathrm{~mm}$, respectively, and the mean relative humidity is $84 \%$. Before conducting our experiment, it was found that the main soil type was 
paddy soils, the bulk density of which was $1.80 \mathrm{~g} \mathrm{~cm}^{-3}$ $(0-15 \mathrm{~cm}), \mathrm{pH}$ was 5.98 , Soil organic carbon (SOC) content was $9.81 \mathrm{~g} \mathrm{~kg}^{-1}$, the total $\mathrm{N}$ content was $1.03 \mathrm{~g} \mathrm{~kg}^{-1}$, and available $\mathrm{P}$ was $1.5 \mathrm{mg} \mathrm{kg}^{-1}$.

In the last four years, local farmers were continuously practicing vegetable cultivation with organic fertilization, which is one of the most common cropping systems in the region. In this system, they were cultivating seasonal vegetables, like summer vegetables sown in April and harvested in July, and winter vegetables sown in the beginning of August and harvested in November. During the growing season, we used the same field practices as the local farmers. No pesticides were applied during the growing season and the weeds were controlled manually.

We have analyzed samples with two different treatments from five plots: three of them were from green house cultivation plots G1, G2 and G3 respectively, and two N5 and N6 open filed cultivation plots. Treatments were arranged in a randomized block design with three replications (Bi et al., 2009; Sikka and Kansal, 1995). All of the samples were collected within three weeks after crops were harvested in December, 2012. Each of the plot with dimensions of $8.66 \times$ $32 \mathrm{~m}$ with 2 -m-wide side walls. The lateral distance between each plot was approximately $200 \mathrm{~m}$. The soil sampling was performed at 3 to 5 random points in each plot to obtain 3-5 separate bulk-soil samples. The soil samples were collected using a stainless-steel corer and homogenized by mixing from a depth of $0^{-15} \mathrm{~cm}$ after the initial surface layer was removed. We have collected $50 \mathrm{~g}$ of soil sample in a sterile plastic bag and immediately placed in liquid nitrogen box in the field. The soil samples were then kept at $4^{\circ} \mathrm{C}$ using ice bag for transport back to the laboratory. For PLFA analysis in the laboratory, the frozen samples were freeze-dried, ground to a fine powder after the removal of root residues, and stored in $10 \mathrm{~mL}$ sterile centrifuge tubes at $-70^{\circ} \mathrm{C}$. Rest of the samples were air-dried and sieved (mesh size $2 \times 2$ $\mathrm{mm}$ ) to remove root fragments and large particles and then stored in polyethylene bags at $4^{\circ} \mathrm{C}$ for subsequent analysis.

\section{Soil chemical properties determination}

The soil $\mathrm{pH}$ was determined with a $\mathrm{pH}$-meter (Mettler Toledo, Shanghai, china) in a supernatant prepared from 10 $\mathrm{g}$ of soil and $25 \mathrm{ml}$ of de-ionized water (Nuñez et al., 2002). Soil moisture content $(H, \%$ of dry weight) was determined gravimetrically using a standard oven-drying method to a constant weight (Nuñez et al., 1994) at $105-110^{\circ} \mathrm{C}$.

The Electrical conductivity (EC) was determined in a conductivity cell by measuring the electrical resistance of a 1:5 (soil:water suspension) solution (Shaw, 1988; Slavich and Petterson, 1993). A KCl reference solution was used to obtain the cell constant. The EC1:5 value at $25^{\circ} \mathrm{C}$ was calculated from the EC metre reading by $\mathrm{EC}_{2.5}$ $\left.(\mathrm{dS} \mathrm{m})^{-1}\right)=1.413 \mathrm{Sx} / \mathrm{K}$, where $\mathrm{S}$ is the measured $\mathrm{EC}$ of the soil suspension, $\mathrm{K}$ is the measured $\mathrm{EC}$ of the $\mathrm{KCl}$ solution, $\mathrm{x}$ is the conversion factor to estimate ECe (saturated paste extract) from $\mathrm{EC}_{1: 5}$, and the conversion factor for clay loams equals 9 (Slavich and Petterson 1993).

The carbon $(\mathrm{C})$, nitrogen $(\mathrm{N})$ and organic matter $(\mathrm{OM})$ in each sample were measured by the redox titration methods described by Klutte and Triegel (Klutte, 1986; Triegel, 1998; Barros et al., 2003). Soil organic matter was hydrolysed with an excess of a mixture containing sulphuric acid and potassium dichromate. The amount of unused potassium dichromate was determined by titration with ferrous sulphate using a diphenylamine indicator to detect unoxidized ferrous iron. Phosphoric acid was added to form a complex with ferric iron and provide a sharper colour change at the endpoint. An extra flask was prepared without soil to standardize the ferrous sulphate and provide blank values. Then, the amount of soil organic matter was measured as total C.

\section{Biological properties determination}

The following three different media were used for the determination of the microorganisms present in the soil samples: Martin's medium for fungi, beef extract peptone medium for bacteria and Gause's No. 1 synthetic medium for actinomycetes. The population of living microorganisms $\left(\mathrm{N}_{0}\right)$ was estimated by a viable count on serial spread plates (Barros et al., 1999; Shatalin et al., 2008). A series of 10-fold dilutions of the samples were prepared with $90 \mathrm{ml}$ of sterilized de-ionized water and $10.0 \mathrm{~g}$ of the soil samples. All glassware was autoclaved, and three independent dilution experiments were performed.

Urease activity was determined by the method described by Gianfreda (Gianfreda et al., 1994) with a minor modification. A $5 \mathrm{~g}$ of air-dried and finely sifted soil (passed through a $1 \mathrm{~mm}$ sieve) was placed in a $50 \mathrm{ml}$ Erlenmeyer flask and incubated with $1 \mathrm{ml}$ methylbenzene for $15 \mathrm{~min}$. Then, $10 \mathrm{ml}$ of $10 \%$ urea and $20 \mathrm{ml}$ of citrate buffer $(\mathrm{pH}=6.7)$ were added to the flask. After mixing them well (shaking for 1-5 min), the flask was placed in an incubator at $37^{\circ} \mathrm{C}$ for $24 \mathrm{~h}$. The mixture was filtered on Fisherbrand Q8 paper, $3 \mathrm{ml}$ of filtrate was diluted to $20 \mathrm{ml}$ with distilled water, and then $4 \mathrm{ml}$ of sodium phenolate $\left(1.35 \mathrm{~mol} \mathrm{~L}^{-1}\right)$ and $3 \mathrm{ml}$ sodium hypochlorite (activated chlorine $0.9 \%$ ) were added. The flask was left for 20 minutes and was then diluted to a constant volume, and the concentration of $\mathrm{NH}_{4}^{+}$ions produced from the hydrolysis of urea was measured spectrophotometrically at $578 \mathrm{~nm}$ via the blue complex. A calibration curve was performed with seven standards $\left(0,0.2,0.6,1.0,1.4,1.8\right.$ and $\left.2.2 \mu \mathrm{g} \mathrm{NH}_{4}{ }^{+}-\mathrm{N} \mathrm{ml}^{-1}\right)$ prepared with ammonium sulphate. A unit of urease 
activity was defined as the quantity of $\mathrm{NH}_{3}-\mathrm{N}$ produced by $1.0 \mathrm{~g}$ of air-dried soil at $37^{\circ} \mathrm{C}$ per hour.

\section{Phospholipid fatty acid (PLFA) analysis}

Using phospholipids fatty acid (PLFA) analysis the soil microbial community was specified. Phospholipids fatty acid (PLFA) was extracted from the soil using Wu et al.'s (2009) method with minor modifications (Wu et al., 2009). Total lipids were extracted from freeze-dried $3 \mathrm{~g}$ of soil sample using single phase buffers approach of potassium phosphate, chloroform and methanol. Phospholipids need to be segregated from neutral and glycolipids on a silica column. Followed by light methylation of phospholipids, PLFA ester was segregated and picked out by Agilent $6890 \mathrm{~N}$ gas chromatograph with MIDI peak identification system (version 4.5; MIDI Inc. Newark, DE). To maintain the internal standard before methylation the fatty acid was added according to 19:0 ratios. For every individual sample, the concentration of single fatty acid methyl esters was demonstrated as nmol PLFA per g soil. All identified PLFAs have been used to calculate total PLFA concentration (nmol PLFA per g C). The following PLFA biomarkers were considered for bacterial origin (gram-positive bacteria by i14:0, i15:0, a15:0, i16:0, a16:0, i17:0, a17:0, gram-negative bacteria by $16: 1 \mathrm{v} 9 \mathrm{c}$, cy $17: 0,18: 1 \mathrm{v} 5 \mathrm{c}, 18: 1 \mathrm{v} 7 \mathrm{c}$, cy $19: 0$, bacteria were represented by the sum of the two) (Frostegaird and Bååth, 1996). Biomarkers 18:3v6c, 18:1v9c and 16:1v5c; and 10Me16:0, 10Me17:0 and 10Me18:0; were used for isolating the fungal and actinomycetes community PLFA, respectively (Zelles, 1997).

\section{Micro-calorimetric measurement}

The microcalorimetric study was performed in a TAM III multi-channel thermal activity microcalorimeter (TA Instruments). All of the calorimetric experiments were performed at $28^{\circ} \mathrm{C}$ in $4.0 \mathrm{ml}$ stainless steel ampoules, which were hermetically closed by Teflon sealing discs to control evaporation and energy loss. A total of $1.2 \mathrm{~g}$ of soil was amended with $0.2 \mathrm{ml}$ of a solution containing $1.25 \mathrm{mg}$ glucose and $1.25 \mathrm{mg}$ of ammonium sulphate to prevent the soil from sinking. This process was performed to stimulate soil microbial activity and to provide the necessary nitrogen and sulphur that microorganisms need to synthesize amino acids. The quantity of soil and the nutrient solution prevents problems related to $\mathrm{CO} 2$ accumulation, and heat flux is obtained from the evaporation in the ampoule (Wang et al., 2010 ; Nuñez et al., 1994).

To quantify the calorimetric results, the time to reach the peak $\left(\mathrm{t}_{\text {peak }}\right)$ and the peak height $\left(\mathrm{P}_{\text {max }}\right)$ were extracted directly from a power-time curve. Additionally, the total heat evolution $(Q T)$ and the growth rate constant $(k)$ were calculated from the power-time curve. The method for quantifying $\mathrm{k}$ is well established (Hashimoto and Takahashi,
1982; Critter et al., 1994; Yamano and Takahashi, 1986). The growth rate constant $k$ could be obtained from a semi-logarithmic plot of the heat rate, according to the modified model by Monod (Wang et al., 2010); $\ln P_{t}=$ $\ln P_{0}+k_{t}$, where $\mathrm{t}$ is the time, $P$ is the power output at time $t$, and $P_{0}$ is the power at time $t=0$. The correlation coefficient $(R)$ and significance probability can be obtained. The dissipation of heat per cell $\left(J_{\mathrm{Q} / \mathrm{N}}\right)$ is obtained by the equation $J_{\mathrm{Q} / \mathrm{N}}=Q_{\mathrm{T}} / \mathrm{N}_{0}$.

\section{Statistical analyses}

Statistical analyses were performed with SPSS 17.0 (SPSS Inc., USA). All results were expressed on a dry weight basis. The data from each plot were subjected to an analysis of variance, and results are expressed as the mean \pm standard deviation of at least three replicates. Data were analysed for significance by Duncan's multiple range test using the SPSS statistical program. Significant differences between the parameters in the open field and greenhouse cultivation were studied with t-tests and marked with " $* P<0.05)$ ".

\section{RESULTS}

\section{Chemical properties of soil samples}

The physicochemical and biological properties of soil samples from the three-green houses and two open fields are summarized in Table 1. It is found that the Electrical conductivity (EC), organic matter $(\mathrm{OM})$ and Humidity $(H)$ all are higher in the greenhouse soil than in the open field soil. But the carbon-nitrogen ratio $(\mathrm{C} / \mathrm{N})$ responses oppositely, higher for the open field soil than the greenhouse. Therefore, to have a better understanding of the relation between both greenhouse and open field soil samples, some statistical analyses are conducted. We have found that, EC, OM, H, N and $\mathrm{C}$ are $48.2 \%(P<0.05)$, 101.3\% $(P<0.005), 107.2 \%(P<0.01), 173.6 \%(P<0.01)$ and $32.14 \%(P<0.05)$, respectively, higher in the soil from the greenhouse than in the soil from the open field cultivation. In contrast, $\mathrm{C} / \mathrm{N}$ displays some interesting findings, and it is $106.5 \%(P<0.01)$ higher in the open field soil compared to that in the greenhouse soil, while the soil $\mathrm{pH}$ does not differ significantly.

\section{Urease activity and microbial population of soil samples}

Urease activities for both greenhouse and open field soil samples were analysed and are summarized in Table 1. A significant urease activity is observed in greenhouse soil. As such, the urease activity is $69.5 \%(P<0.01)$ higher in the greenhouse soil than in the open-field soil (Table 1). The number of viable microorganism per gram of soil (N0) estimated by a viable count is shown in Table 2, and the microbial diversity is shown in Fig. 1. The bacterial 
Table 1: Physicochemical and biological properties of the soil samples of this study

\begin{tabular}{|c|c|c|c|c|c|c|c|c|}
\hline Samples & $E C^{a *}\left(d^{2} m^{-1}\right)$ & $p H$ & $O M^{b *}\left(g_{k g}^{-1}\right)$ & $H^{\mathrm{c*}}(\%)$ & $\begin{array}{c}\text { Urease activity* } \\
\left(\mathrm{NH}^{4+}-\mathrm{N} / \mathrm{g}^{-1} \mathbf{h}^{-1}\right)\end{array}$ & $C^{d *}$ & $\mathrm{~N} \mathrm{~d}^{*}(\%)$ & $\mathrm{C} / \mathrm{N}$ \\
\hline G1 & $2.91 \pm 0.02 c$ & $6.92 \pm 0.12 b$ & $14.82 \pm 0.40 c$ & $12.10 \pm 0.60 c$ & $9.84 \pm 0.11 c$ & $8.34 \pm 0.02 b$ & $0.28 \pm 0.02 b$ & 29.78 \\
\hline G2 & $2.52 \pm 0.04 \mathrm{c}$ & $6.75 \pm 0.13 b$ & $13.68 \pm 0.24 c$ & $11.90 \pm 0.40 c$ & $9.07 \pm 0.01 \mathrm{c}$ & $7.98 \pm 0.02 b$ & $0.26 \pm 0.02 b$ & 30.69 \\
\hline G3 & $2.09 \pm 0.01 b$ & $6.42 \pm 0.17 a b$ & $11.48 \pm 0.50 c$ & $10.20 \pm 0.90 c$ & $7.64 \pm 0.08 b$ & $8.12 \pm 0.02 b$ & $0.24 \pm 0.02 b$ & 33.83 \\
\hline N5 & $1.47 \pm 0.01 \mathrm{a}$ & $6.51 \pm 0.09 a b$ & $4.72 \pm 0.20 a$ & $4.30 \pm 0.07 a$ & $4.21 \pm 0.03 a$ & $6.34 \pm 0.01 \mathrm{a}$ & $0.10 \pm 0.01 a$ & 63.40 \\
\hline N6 & $1.90 \pm 0.01 b$ & $6.36 \pm 0.14 a$ & $8.52 \pm 0.12 b$ & $6.70 \pm 0.20 b$ & $6.23 \pm 0.07 \mathrm{~b}$ & $5.98 \pm 0.01 a$ & $0.09 \pm 01 \mathrm{a}$ & 66.44 \\
\hline
\end{tabular}

Values are given as the mean \pm S.D., $n=3-5$; values within the same column not followed by the same letter differ significantly $(P<0.05)$, and significant differences between Group N and Group G are shown as * $(P<0.05),{ }^{a}$ The electrical conductivity, ${ }^{\mathrm{b}}$ The organic matter content, ${ }^{\mathrm{c} P e r c e n t a g e}$ humidity of soil samples. ${ }^{\mathrm{P}}$ Percentage of carbon and nitrogen and $\mathrm{C} / \mathrm{N}$ carbon nitrogen ratio

Table 2: Populations of soil bacteria, actinomycetes and fungi

\begin{tabular}{lcccc}
\hline Samples & \multicolumn{4}{c}{ Number of CFU per g of dry soil } \\
\cline { 2 - 5 } & ${\text { Bacteria* }\left(\times 10^{6}\right)}^{*}$ Fungi $\left(\times 10^{5}\right)$ & Actinomycete* $\left(\times 10^{6}\right)$ & N0* $\left(\times 10^{6}\right)$ \\
\hline G1 & $1.95 \pm 0.31 \mathrm{c}$ & $1.70 \pm 0.14 \mathrm{~d}$ & $5.55 \pm 0.7 \mathrm{c}$ & $8.82 \pm 1.60 \mathrm{c}$ \\
G2 & $1.80 \pm 0.37 \mathrm{bc}$ & $1.50 \pm 0.07 \mathrm{dc}$ & $2.50 \pm 0.12 \mathrm{~b}$ & $7.50 \pm 1.10 \mathrm{c}$ \\
G3 & $1.75 \pm 0.44 \mathrm{bc}$ & $1.10 \pm 0.04 \mathrm{~b}$ & $0.39 \pm 0.03 \mathrm{a}$ & $4.36 \pm 0.56 \mathrm{~b}$ \\
N5 & $0.88 \pm 0.13 \mathrm{a}$ & $0.26 \pm 0.02 \mathrm{a}$ & $0.34 \pm 0.07 \mathrm{a}$ & $1.53 \pm 0.16 \mathrm{a}$ \\
N6 & $1.35 \pm 0.29 \mathrm{~b}$ & $1.35 \pm 0.17 \mathrm{c}$ & $1.83 \pm 0.38 \mathrm{a}$ \\
\hline
\end{tabular}

The mean value of microbial numbers in the soil samples was measured by a viable count. Each soil sample was counted for at least three independent measurements. Bacteria, actinomycetes and fungi were counted CFU, colony forming units; NO, number of viable microorganisms per gram of soil dry weight. Values are as the mean \pm S.D., $n=3-5$; values within the same column not followed by the same letter differ significantly $(P<0.05)$, and significant differences between Group N and Group $G$ are shown as * $(P<0.05)$

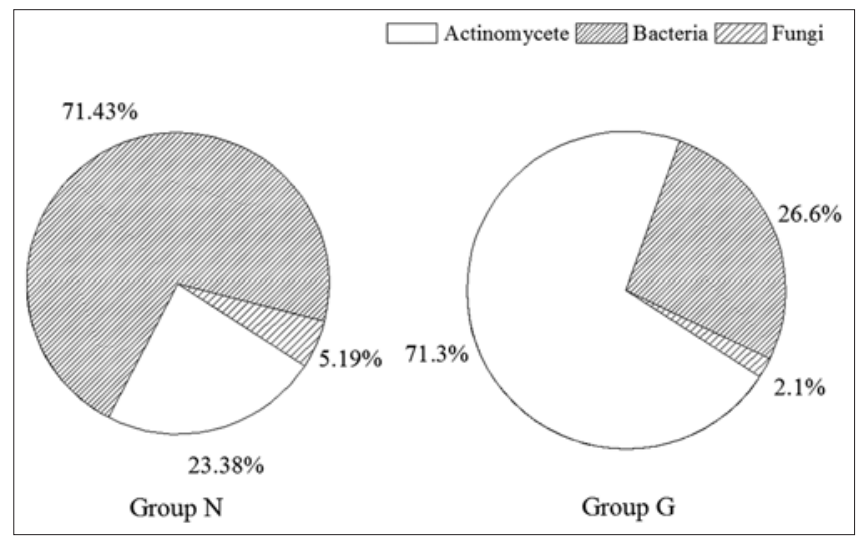

Fig 1. The diversity of microorganisms in soils under cultivation in an open field (Group N) or in a greenhouse (Group G).

population is significantly higher $(P<0.05)$, and the actinomycete population is 12 -fold higher $(P<0.001)$ in the greenhouse soil than in the open field soil. There is no significant difference in the fungal population between the two groups.

\section{Soil microbial activity in heat profiles}

Power-time curves are well-stablished method to indicate the typical microbial growth activity (Fig. 2). The heat evolution exponentially increases after the lag phase, where it was followed by a stationary phase and a decline phase. The results indicate that the lag phase of greenhouse treatment (G1, G2 and G3) is shorter than that of the open field treatment (N5 \& N6) (Fig. 2). Among all the treatments, we have found that N5 treatment soil has the longest stationary phase. The total heat release $Q_{T}\left(\mathrm{~J} \mathrm{~g}^{-1}\right)$, maximum heat flow $P_{\max }(\mu \mathrm{W})$ and growth rate constant $k$ $\left(b^{-1}\right)$ are higher in $\mathrm{G}$ treatment group than the $\mathrm{N}$ treatment

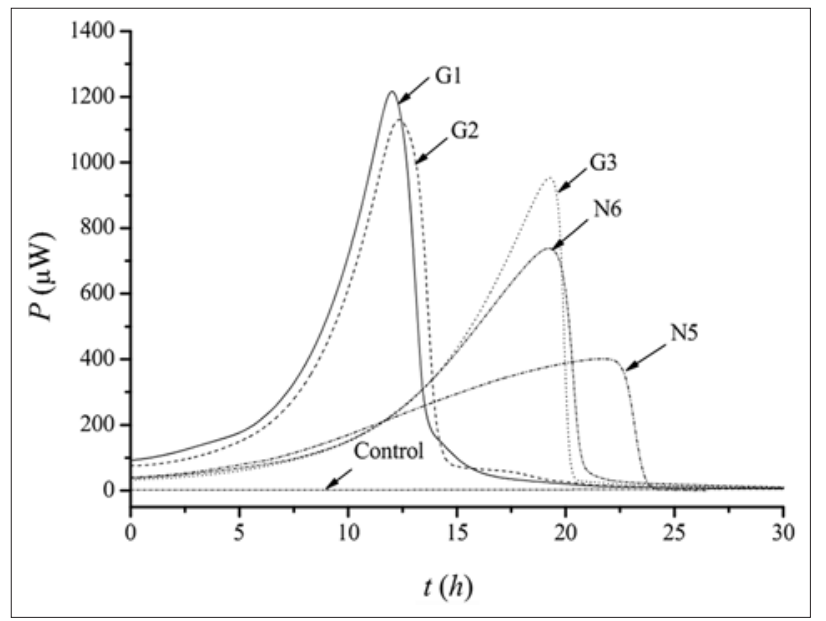

Fig 2. Power $(P)$-time $(t)$ curves of the $1.2 \mathrm{~g}$ soil samples from different area at $28^{\circ} \mathrm{C}$ in the presence of $1.25 \mathrm{mg}$ glucose and $1.25 \mathrm{mg}$ of $\left(\mathrm{NH}_{4}\right)_{2} \mathrm{SO}_{4}$.

group (Table 3). Whereas, time to reach the peak $\left(\mathrm{t}_{\max }\right)$ and cell specific heat rate $J_{Q / N}\left(\mathrm{~J} \mathrm{cell}^{-1}\right)$ are lower in $\mathrm{G}$ treatment group compared to the $\mathrm{N}$ treatment group. Sample $\mathrm{G} 1$ has the highest $P_{\max }(1246.07 \mu \mathrm{W})$ and the lowest $\mathrm{t}_{\max }(11.86$ b); in contrast, sample $\mathrm{N} 5$ has the lowest $P_{\text {max }}(411.03 \mu \mathrm{W})$ and the highest $t_{\max }(21.78 \mathrm{~b})$. There is a significant difference in the thermogenic properties between the greenhouse soil and the open-field soil with respect to $Q T, k$ and $J_{Q / N}$; $k(P<0.001)$ is larger, and $J_{Q / N}(P<0.005)$ is smaller for the greenhouse soil. There is no significant difference in $Q_{T}$ between the two groups.

The results of single linear regression analyses performed with the data of the physicochemical and heat profiling properties involved in this work are shown in Figs 3 and 4. 
Table 3: Thermogenic and biological properties of sediment samples

\begin{tabular}{|c|c|c|c|c|c|c|c|}
\hline $\begin{array}{l}\text { Soil } \\
\text { samples }\end{array}$ & $Q T\left(\mathrm{~J} \mathrm{~g}^{-1}\right)$ a & $P_{\max }(\mu \mathrm{W})^{\mathrm{b} *}$ & InP-t (Involved period) ${ }^{c}$ & $\mathbf{R}^{\mathbf{d}}$ & $k\left(h^{-1}\right)^{e *}$ & $t_{\max }(\mathrm{h}) \mathrm{f}$ & $J Q / N\left(J\right.$ cell $\left.^{-1}\right) \mathrm{g}^{*}$ \\
\hline G1 & $17.86 \pm 0.17 c$ & $1246.10 \pm 33.25 d$ & $\ln P=3.44+0.37 t(7.30 h-11.20 h)$ & 0.99 & $0.368 \pm 0.02 d$ & $11.86 \pm 0.60 b$ & $2.02 \times 10^{-6}$ \\
\hline G2 & $17.29 \pm 0.28 c$ & $1151.70 \pm 20.09 d$ & $\ln P=3.33+0.34 t(6.50 h-10 h)$ & 0.99 & $0.342 \pm 0.03 d$ & $12.00 \pm 0.52 b$ & $2.31 \times 10^{-6}$ \\
\hline G3 & $16.16 \pm 0.31 a b$ & $971.50 \pm 41.68 c$ & $\ln P=2.98+0.24 t(6.10 h-16.60 h)$ & 0.99 & $0.244 \pm 0.02 c$ & $18.70 \pm 0.68 c$ & $3.71 \times 10^{-6}$ \\
\hline N5 & $15.82 \pm 0.14 a$ & $411.00 \pm 19.28 a$ & $\ln P=3.58+0.04 t(13.10 h-19.50 h)$ & 0.99 & $0.037 \pm 0.01 a$ & $21.80 \pm 0.88 d$ & $10.30 \times 10^{-6}$ \\
\hline N6 & $16.47 \pm 0.24 b$ & $753.40 \pm 12.89 b$ & $\ln P=3.18+0.14 t(5.20 h-14.70 h)$ & 0.99 & $0.143 \pm 0.01 b$ & $18.90 \pm 0.24 d c$ & $9.02 \times 10^{-6}$ \\
\hline
\end{tabular}

Values are as the mean \pm S.D., $n=3-5$; values within the same column not followed by the same letter differ significantly $(P<0.05)$, and significant differences between Group N and Group $G$ are shown as * $(P<0.05)$. ${ }^{\mathrm{T}}$ The total heat generated by microbial growth reactions, ${ }^{\mathrm{b}}$ The maximum heat flow rate of the microbial growth reaction, 'Linear fit equation and its involved period for the calculation of $k,{ }^{\mathrm{d}}$ Correlation coefficient for the linear fit, ${ }^{\mathrm{e}}$ The microbial growth rate constant, Time to reach the peak. ${ }^{9}$ The cell specific heat rate

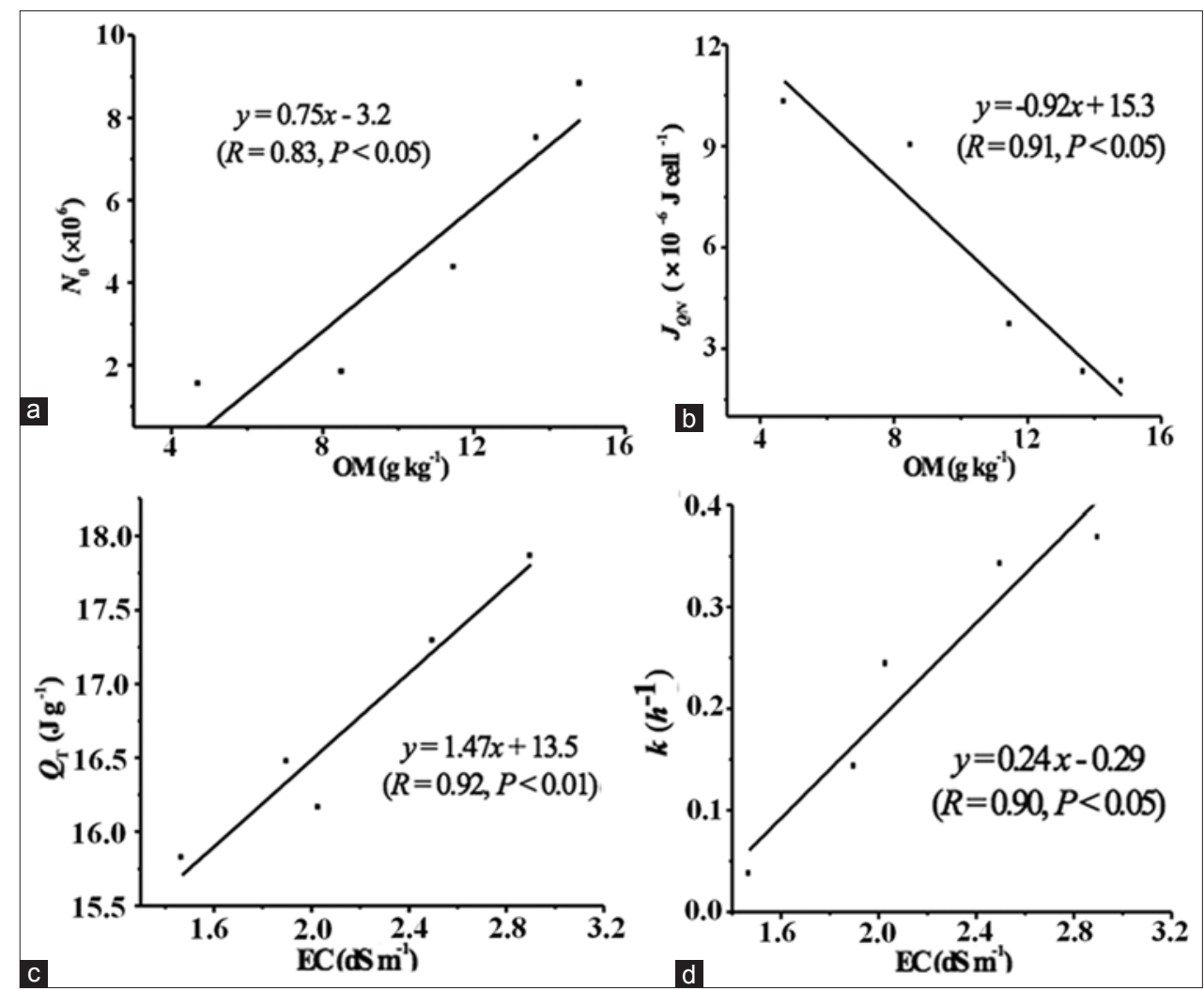

Fig 3. Linear regression analyses. (a) Linear regression analyses of OM and NO. (b) Linear regression analyses of OM and JQ/N. (c) Linear regression analyses of $Q T$ and $\mathrm{EC}$. (d) Linear regression analyses of $\mathrm{EC}$ and $k$.

We have observed the correlations between number of viable microorganisms per gram of soil $\mathrm{N}_{0}$, cell specific heat rate $J_{Q / N}\left(J\right.$ cell $\left.^{-1}\right)$ and organic matter content $O M\left(\mathrm{~g} \mathrm{~kg}^{-1}\right)$ (Fig. $\left.3 \mathrm{a} \& \mathrm{~b}\right)$ and between the electrical

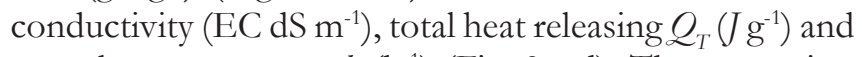
growth rate constant $k\left(\mathrm{~h}^{-1}\right)$ (Fig. $\left.3 \mathrm{c}, \mathrm{d}\right)$. The regression analysis results show the positive correlation, whereas the relationship between $O M$ and $J_{\mathrm{Q} / \mathrm{N}}$ is observed highly negative (Fig. 3b). Meanwhile, the correlation between urease activity $\left(\mathrm{NH}_{4}^{+}-\mathrm{N} / \mathrm{g}^{-1} \mathrm{~h}^{-1}\right)$ and the growth rate constant $k\left(\mathrm{~h}^{-1}\right)$ is shown highly positive (Fig. 4). These findings have a potential implication to the understanding of the microbial growth metabolism activity and the soil quality in both treatment systems.

\section{Microbial community structure}

Complete mean value of PLFA concentrations ranges from 129.76 to142.54 $\mathrm{nmol} \mathrm{g}^{-1}$ (Table 4). Overall PLFA concentration is significantly greater in G1, G2 and G3 treatments than in the N5 and N6 management systems $(P<$ 0.05). The G (G1, G2 and G3) group shows a higher PLFA concentration, followed by N group cultivation system (N5 \& N6). The composition of the soil microbial community differed among management systems, as indicated by PLFAs. Overall PLFAs, fungal PLFAs, Actinomycete PLFAs, and mono-unsaturated PLFA markers of $\mathrm{G}^{-}$and $\mathrm{G}^{+}$bacteria are much higher for $\mathrm{G}$ plots than for $\mathrm{N}$ plots. There were significant differences in the bacterial and actinomycete PLFA biomarker contents between different 
Table 4: Phospholipid fatty acid (PLFA) profiles of soil samples (0-15 cm deep) under two management systems

\begin{tabular}{lccccc}
\hline Biomarker PLFA & G1 & G2 & G3 & N5 & N6 \\
\hline Total PLFAs (nmol g-1) & $142.54 \pm 2.98 \mathrm{a}$ & $140.56 \pm 2.68 \mathrm{~b}$ & $141.57 \pm 2.67 \mathrm{c}$ & $128.76 \pm 0.88 \mathrm{~d}$ & $129.76 \pm 0.77 \mathrm{e}$ \\
Fungal PLFAs $\left(\mathrm{nmol} \mathrm{g}{ }^{-1}\right)$ & $20.43 \pm 0.65 \mathrm{a}$ & $20.53 \pm 0.86 \mathrm{~b}$ & $19.87 \pm 0.45 \mathrm{c}$ & $20.57 \pm 0.55 \mathrm{~d}$ & $19.93 \pm 0.45 \mathrm{e}$ \\
Gram-negative (G-) PLFAs $\left(\mathrm{nmol} \mathrm{g}{ }^{-1}\right)$ & $60.63 \pm 0.35 \mathrm{a}$ & $59.43 \pm 0.76 \mathrm{~b}$ & $58.95 \pm 0.55 \mathrm{c}$ & $49.42 \pm 0.35 \mathrm{~d}$ & $47.63 \pm 0.43 \mathrm{e}$ \\
Gram-positive (G+) PLFAs $\left(\mathrm{nmol} \mathrm{g}{ }^{-1}\right)$ & $31.73 \pm 0.75 \mathrm{a}$ & $30.56 \pm 0.96 \mathrm{~b}$ & $29.85 \pm 0.44 \mathrm{c}$ & $27.52 \pm 0.75 \mathrm{~d}$ & $26.89 \pm 0.44 \mathrm{e}$ \\
Actinomycete PLFAs $\left(\mathrm{nmol} \mathrm{g}{ }^{-1}\right)$ & $23.43 \pm 0.75 \mathrm{a}$ & $22.83 \pm 0.63 \mathrm{~b}$ & $21.53 \pm 0.55 \mathrm{c}$ & $19.43 \pm 0.85 \mathrm{~d}$ & $18.83 \pm 0.33 \mathrm{e}$ \\
\hline
\end{tabular}

Values (means standard errors, $n=4)$ within a row followed by different letters are significantly different $(P<0.05)$ by one-way ANOVA followed by Duncan's multiple range test

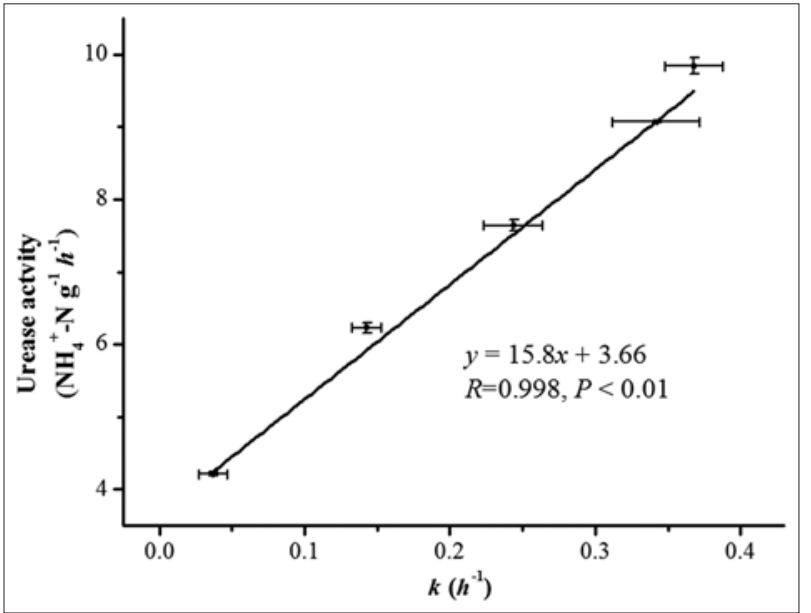

Fig 4. The linear curve fit of the urease activity against the growth rate constant $(k)$. The data are expressed as the mean $\pm S D, n=3-5$.

cultivation treatments $(P<0.05)$. Meanwhile, there are no significant differences in the fungal PLFAs in both treatment system $(P>0.05)$. The highest bacteria $\left(G^{-}, G^{+}\right)$ and actinomycete PLFA biomarker content is found in G1 soil treated with green house cultivation $(60.63,31.73$ and $23.43 \mathrm{nmolg}^{-1}$ respectively), whereas the lowest is found in N6 soil treated with open field cultivation (47.63, 26.89 and $18.83 \mathrm{nmolg}^{-1}$ respectively) (Table 4). With respect of PLFA, they follow the series G1 > G2 > G3 > N5 > N6. These are consistent with the heat profiling, urease activity and soil microbial population in the two groups of soil.

\section{DISCUSSION}

Greenhouse cultivation is dependent on fertilization and alters the soil properties (e.g., the selection and amount of fertilizers) (Table 1) ( Ge et al. 2013; Barros et al., 2016b). The EC values in the greenhouse soil are higher than those in the open-field soil, which can be attributed to the fact that there was no soil leaching due to rainfall that occurred under the greenhouse conditions, and the evaporation of the soil water resulted in salt accumulation (Shrestha, 2006).

Many studies have suggested that soil enzyme activities can differentiate soil management practices (Garcia-Ruiz et al., 2009). Urease in the soil catalyses the degradation of urea into $\mathrm{CO}_{2}, \mathrm{~N}_{2} \mathrm{O}, \mathrm{CH}_{4}$ and $\mathrm{NH}_{3}$. The urease activity, which has widely been used as an indicator in the evaluation of soil quality and soil microbial activity, was higher under the greenhouse cultivation conditions than under the open field cultivation conditions. This observation is consistent with the report by Signor and Wu et al. (Signor et al., 2013; Wu et al., 2011). Greenhouse cultivation leads to a higher soil OM than open-field cultivation. High quantities of organic matter may either promote or suppress urease activity via soil acidification and salinization because soil enzymes are strongly affected by soil $\mathrm{pH}$ and salinity (Dong et al., 2014; Lin et al., 2010; Haynes and Rietz, 2003; Tabatabai and Ekenler, 2003).

Microbial diversity and population are the key parameters of soil structure and fertility. In our study, the microbial biomass was higher in the greenhouse soil than the openfield soil with positive correlations between $\mathrm{N}_{0}$ and $\mathrm{OM}$ in both cases (Fig. 3a). Followed by, highly positive correlations are identified between the electrical conductivity EC, total heat releasing $\mathrm{Q}_{T}$ and growth rate constant $k$. This also supports the research hypothesis that the green house $(\mathrm{G})$ soil contains more microbial biomass than the open field (N) soil. Several studies have documented that high organic matter increases the soil microbial population (Belay et al., 2002; Fujii et al., 2007; Shen et al., 2010; Ge et al., 2013; Tobias et al., 2016). The bacterial population and the actinomycetes in groups $\mathrm{G}$ and $\mathrm{N}$ differed significantly. There was no significant difference in the fungal population between groups $\mathrm{G}$ and $\mathrm{N}$. The differences originated from the different nutritional sources of the microorganisms.

PLFA signatures characterise the soil microbial community (Dong et al., 2014; Tobias et al., 2016). The relatively high total PLFA levels in our G plots (Table 4) indicates high microbial biomass; it has been shown that organicallymanaged systems promote the microbial biomass (Ge et al., 2013; Dong et al., 2014; Tobias et al., 2016) through covering the crops and $\mathrm{C}$ enhanced the soil nutrients. The fungal community is more or less similar in both G and N group's soil treatment. Meanwhile, bacterial and actinomycete communities were constant in both treatment systems. This might be attributed to a positive nutrient balance due to the same fertilizer treatment. On the other hand, the PLFA concentration of bacteria and actinomycetes community varies from a high value to a low 
value as the group changes from $\mathrm{G}$ to $\mathrm{N}$ (Ge et al., 2013; Dong et al., 2014).

Furthermore, our PLFA concentration is consistent with heat profiling, urease activity and microbial population of soil. It has been shown that the green house cultivation promotes more diversified biomass than the open field cultivation. The biogeochemical pattern varies with different treatment system as well (Barros et al., 2016b; Belay et al., 2002; Fujii et al., 2007). Therefore, it supports our research hypothesis that the green house cultivation system could be a sustainable management system to maintain a good soil health quality and a green food production (Barros et al.,2014; Dong et al., 2014).

Bacteria and actinomycetes are closer to the fine particle organic matter (POM) fraction, while fungi are closer to the coarse POM fraction (Wienhold et al., 2006; Dong et al., 2014). Data from groups $N$ and $G$ show that the fungal proportion in $\mathrm{N}_{0}$ decreases from $5.19 \%$ to $2.1 \%$, and the proportion of actinomycetes in $\mathrm{N}_{0}$ rises from $23.38 \%$ to $71.3 \%$ (Fig. 1). The increased $\mathrm{EC}$ has an effect on the microbial community, shifting it towards a bacteria- and actinomycete-dominated community (Wienhold et al., 2006; Dong et al., 2014). These results differ from a report by Pankhurst et al. (2001), who observed a less active and less functionally diverse bacteria-dominated community. Their observation was based on a saline and alkaline soil with an EC value greater than $4 \mathrm{ds} \mathrm{m}^{-1}$, which constituted a much more selective soil environment.

The addition of nutrient solutions induces a rapid increase in the heat flow rate in all of the soil samples (Fig. 2). The rapid increase after the lag phase is followed by the decline of heat flow to zero. The heat curves of the various soil samples were highly variable, indicative of complications within the soil. $Q_{T}$ is the sum of the catabolic and anabolic processes in soil and reflects the ability of the microbial community to facilitate these processes (Barros and Feijóo, 2003; Barros et al., 2016a; Armando et al. 2017). However, the microbial activity measured as the total heat does not show a significant difference between the two cultivation methods $(\mathrm{P}>0.05)$, which could be explained by the fact that $Q_{T}$ is largely determined by the amount of oxygen (in the ampoule), which produces approximately $15 \mathrm{~J}$ of heat according to Thornton's rule (Hansen et al., 2004). Thus, after the oxygen in the ampoule is consumed, anaerobic respiration by soil microorganisms should be a key metabolic pathway for the growth on glucose. The $Q_{T}$, therefore, encompasses the heat output from both aerobic and anaerobic respiration. $Q_{T}$ is positively $(R=0.912$, $P<0.05)$ correlated with $N_{0}$ in this study. Rich organic matter stimulates the microbial population, and organic matter could be degraded more efficiently by the most numerous microbes (Wienhold et al., 2006; Barros et al., 2015); thus, more metabolic heat would be released into the environment.

Differences in soil chemical properties lead to differences in microbial structure and quantity, which would be reflected in the thermogenic activities by microorganisms. Positive correlations are found between EC, $\mathrm{Q}_{T}$ and $k$ (Fig. 3c, d). The EC of soil was used to estimate the total quantity of dissolved solutes in the soil (Rhoades et al., 1990; Rose et al., 2006). The results suggest that salt in soil may stimulate the growth and heat output of microorganisms in a direct or indirect manner. Generally, the ion concentration in the soil affects microbial activity via cation distribution, and the cation exchange capacity is significantly correlated with the variations of the substrate utilization patterns of the microorganisms (Pankhurst et al., 2001).

In this study, we investigated the relationship between $\mathrm{OM}$ and $J_{\mathrm{Q} / \mathrm{N}}$ and observed a highly negative correlation (Fig. $3 \mathrm{~b}$ ). $J_{\mathrm{Q} / \mathrm{N}}$ represents the dissipation of the heat per cell unit, and a higher $J_{\mathrm{Q} / \mathrm{N}}$ is associated with a less efficient metabolism. A lower dissipation yield indicates a more efficient metabolism (Barros et al., 2003; Yu et al., 2009). The correlation between $\mathrm{OM}$ and $\mathrm{J}_{\mathrm{Q} / \mathrm{N}}$ implies that the amount of organic matter in the soil is connected to the efficiency of microbes to incorporate carbon into their biomass. Higher soil organic matter indicates more efficient carbon assimilation into the biomass. Several studies have documented that mineral fertilizer or organic manure increases soil microbial diversity (Barros et al., 2016b; Barros et al., 2014; Ge et al., 2013; Belay et al., 2002; Fujii et al., 2007; Shen et al., 2010). The increased soil microbial diversity could transform carbon from organic debris into biomass at a lower energy cost, thus building a higher microbial biomass (Mader et al., 2010). The positive correlation between $\mathrm{OM}$ and the biomass $\left(\mathrm{N}_{0}\right)$ shown in Fig. 3 (a) confirms the above explanation.

The microbial activity also has a significant impact on the urease activity in the soil as shown from the high positive correlation between $k$ and urease activity in Fig. 4. Soil enzyme activities are regulated by microorganisms in a direct and indirect manner. On the one hand, microorganisms increase production and secretion to affect the enzyme activity in the soil (Guo et al., 2012; Aon and Colaneri, 2001). On the other hand, microorganisms alter the physicochemical conditions of the soil directly via their activity (Sinsabaugh, 1994).

\section{CONCLUSIONS}

We have successfully introduced a combined novel approach, consisting of microcalorimetric technique with 
PLFA, to study the changes of soil microbial community and the relationship between physicochemical properties and the diversity of the microbial community in $G$ and $\mathrm{N}$ treatment systems. Greenhouse cultivation alters soil properties as a result of long-term film covers. The microbial population in a greenhouse soil is higher than that in the open field, and the microbial community shifts towards a bacteria- and actinomycete-dominated community. The microbial activities that show thermogenic properties, urease activity and PLFA concentration are higher in the greenhouse soil than in the open field soil. A high organic matter content in the soil supports a high microbial population and diversity, and it is favourable for the maintenance of the effective function of microbes to incorporate carbon into their biomass. It will lead us to practice the sustainable management system to grow more foods. Moreover, this would be a significant technique for the decision maker to choose the potential cultivation method for sustainable green food development program.

\section{ACKNOWLEDGEMENTS}

This work is supported in part by grants from the Fundamental Research Funds from the Central Universities (CZQ15010, DUT15QY54 \& DUT14QY48), the National Science \& Technology Pillar Program (2015BAB01B04), International Joint Key Project from National Natural Science Foundation of China (40920134003), National Natural Science Foundation of China (41603069, 41503067 \& 41273092), National Outstanding Youth Research Foundation of China (40925010) and the Research Grant Council of Shenzhen Government (JCYJ20160531191442288).

\section{AUTHOR CONTRIBUTION}

Ke Chen, Mohammad Russel \& Liu Changrui designed, conducted the experiments and wrote the paper. Yao Jun, Liu Lifen, Md. Mahbub Alam and Shangli Kim helped us to improve the data analysis, correction and edited the whole manuscript according to their expertise.

\section{REFERENCES}

Anna, B. C., A. B. Maria, N. Isabel, D. L. Martina, L. L. Maria and G. Paola. 2015. Changes in microbial community structure and functioning of a semiarid soil due to the use of anaerobic digestate derived composts and rosemary plants. Geoderma. 245-246: 89-97.

Aon, M. A. and A. C. Colaneri. 2001. Temporal and spatial evolution of enzymatic activities and physico-chemical properties in an agricultural soil. Appl. Soil Ecol. 18: 255-270.

Armando, H. G., M. H. Anke and H. Sebastian. 2017. Isothermal microcalorimetry for rapid viability assessment of freeze-dried
Lactobacillus reuteri. Process Biochem. 55: 49-54.

Barros, N., L. D. Hansen, V. Piñeiro and P. Vikegard. 2016a. Calorimetry measures the response of soil organic matter biodegradation to increasing temperature. J. Therm Anal. Calorim. 123(3): 2397-2403.

Barros, N., L. D. Hansen, V. Piñeiro, C. Pérez-Cruzado, M. Villanueva, J. Proupín and J. A. Rodríguez-Añon. 2016b. Factors influencing the calorespirometric ratios of soil microbial metabolism. Soil Biol. Biochem. 92: 221-229.

Barros, N., V. Piñeiro and L. D. Hansen. 2015. Calorespirometry: A novel tool to assess the effect of temperature on soil organic matter decomposition. Thermochim. Acta. 618: 15-17.

Barros, N., G. A. Merino, P. M. Martín, C. C. Pérez and L. Hansen. 2014. Changes in soil organic matter in a forestry chronosequence monitored by thermal analysis and calorimetry. Span J Soil Sci. 4: $239-253$.

Barros, N., S. Feijóo, A. Simoni, S. A. M. Critter and C. Airoldi. 2012. Interpretation of the metabolic enthalpy change, $\Delta \mathrm{Hmet}$, calculated for microbial growth reactions in soils. J. Therm. Anal. Calorim. 63(2): 577-588.

Barros, N. and S. Feijóo. 2003. A combined mass and energy balance to provide bio indicators of soil microbiological quality. Biophys. Chem. 104: 561-572.

Barros, N., S. Feijoo and S. Fernandez. 2003. Microcalorimetric determination of the cell specific heat rate in soils: Relationship with the soil microbial population and biophysic significance. Thermochim. Acta. 406: 161-170.

Barros, N., S. Feijóo, J. A. Simoni, A. G. S. Prado, F. D. Barboza and C. Airoldi. 1999. Microcalorimetric study of some Amazonian soils. Thermochim. Act. 328: 99-103.

Barros, N., S. Feijóo and R. Balsa. 1997. Comparative study of the microbial activity in different soils by the micro calorimetric method. Thermochim. Acta. 296: 53-58.

Belay, A., A. S. Claassens and F. C. Wehner. 2002. Effect of direct nitrogen and potassium and residual phosphorus fertilizers on soil chemical properties, microbial components and maize yield under long-term crop rotation. Biol. Fertil. Soils. 35(6): 420-427.

Bi, L., B. Zhang, G. Liu, Z. Li, Y. Liu, C. Ye, X. Yu, T. Lai, J. Zhang, Y. Jianmin and L. Yin. 2009. Long-term effects of organic amendments on the rice yields for double rice cropping systems in subtropical China. Agric. Ecosys. Environ. 129: 534-541.

Critter, S. A. M., S. S. Freitas and C. Airoldi. 2004a. Comparison of microbial activity in some Brazilian soils by micro calorimetric and respirometric methods. Thermochim. Acta. 410: 35-46.

Critter, S. A. M., J. D. Simoni and C. Airoldi. 1994. Microcalorimetric study of glucose degradation in some Brazilian soils. Thermochim. Acta. 232(1): 145-154.

Dong, W. Y., X. Y. Zhang, X. Q. Dai, X. L. Fu, F. T. Yang, X. Y. Liu, X. M. Sun, X. F. Wen and S. Sean. 2014. Changes in soil microbial community composition in response to fertilization of paddy soils in subtropical China. Appl. Soil Ecol. 84: 140-147.

Frostegård, Å. and E. Bååth. 1996. The use of phospholipid fatty acid analysis to estimate bacterial and fungal biomass in soil. Biol. Fertil. Soils. 22: 59-65.

Fujii, T., H. Y. Chu, S. Morimoto, X. G. Lin, K. Yagi, J. L. Hu and J. B. Zhang. 2007. Community structure of ammonia-oxidizing bacteria under long-term application of mineral fertilizer and organic manure in a sandy loam soil. Appl. Environ. Microb. 71(2): 485-491.

Gamalero, E., L. Avidano, G. P. Cossa and E. Carraro. 2005. Characterization of soil health in an Italian polluted site by using microorganisms as bio indicators. Appl. Soil Ecol. 30: 21-33. 
Garcia-Ruiz, R., V. Ochoa, B. Vinegla, M. B. Hinojosa, R. PenaSantiago, G. Liebanas, J. C. Linares and J. A. Carreira. 2009. Soil enzymes, nematode community and selected physicochemical properties as soil quality indicators in organic and conventional olive oil farming: Influence of seasonality and site features. Appl. Soil Ecol. 41: 305-314.

Ge, T., X. Chen, H. Yuan, B. Li, H. Zhu, P. Peng, K. Li, L. J. Davey and J. Wu. 2013. Microbial biomass, activity, and community structure in horticultural soils under conventional and organic management strategies. Eur. J. Soil Biol. 58: 122-128.

Gianfreda, L., F. Sannino, N. Ortega and P. Nannipieri. 1994. Activity of free and immobilized urease in soil - Effects of pesticides. Soil Biol. Biochem. 26: 777-784

Guo, H., J. Yao, M. Cai, Y. Qian, Y. Guo, H. H. Richnow, R. E. Blake, S. Doni and B. Ceccanti. 2012. Effects of petroleum contamination on soil microbial numbers, metabolic activity and urease activity. Chemosphere. 87(11): 1273-1280.

Hansen, L. D., C. Macfarlane, N. McKinnon, B. N. Smith and R. S. Criddle. 2004. Use of calorespirometric ratios, heat per $\mathrm{CO}_{2}$ and heat per O-2, to quantify metabolic paths and energetics of growing cells. Thermochim. Acta. 422: 55-61.

Hashimoto, M. and K. Takahashi. 1982. Calorimetric studies of microbial growth: quantitative relation between growth thermograms and inoculum size. Agri Biol Chem. 46: 1559-1564.

Haynes, R. J. and D. N. Rietz. 2003. Effects of irrigation-induce salinity and sodicity on soil microbial activity. Soil Biol. Biochem. 35(6): 845-854.

Klutte, A. 1986. Methods of Soil Analysis, American. Society of Agronomy, Madison, WI.

Li, X. L., Z. P. Hao, P. Christie, F. Zheng, J. L. Li, Q. Chen and J. G. Wang. 2009. Excessive nitrogen inputs in intensive greenhouse cultivation may influence soil microbial biomass and community composition. Commun. Soil Sci. Plan. 40: 2323-2337.

Lin, X. G., W. S. Shen, W. M. Shi, J. Min, N. Gao, H. Y. Zhang, R. Yin and X. H. He. 2010. Higher rates of nitrogen fertilization decrease soil enzyme activities, microbial functional diversity and nitrification capacity in a Chinese polytunnel greenhouse vegetable land. Plant Soil. 337(1): 137-150.

Mader, P., A. Fliessbach, D. Dubois, L. Gunst, P. Fried and U. Niggli. 2002. Soil fertility and biodiversity in organic farming. Science. 296: 1694-1697.

Nannipieri, P., J. Ascher, M. T. Ceccherini, L. Landi, G. Pietramellara and G. Renella. 2003. Microbial diversity and soil functions. Eur. J. Soil Sci. 54(4): 655-670.

Nuñez, R. L., A. J. A. Rodriguez, C. J. Proupin and F. O. Nunez. 2006. Microcalorimetric study of changes in the microbial activity in a humic Cambisol after reforestation with eucalyptus in Galicia (NW Spain). Soil Biol. Biochem. 38(1): 115-124.

Nuñez, L., F. O. Nuñez, J. A. R. Anon and J. P. Castineiras. 2002. The influence of some physicochemical parameters on the microbial growth in soils. Thermochim. Acta. 394: 123-131.

Nuñez, L., N. Barros and I. Barja. 1994. A kinetic-analysis of the degradation of glucose by soil-microorganisms studied by microcalorimetry. Thermochim. Acta. 237(1): 73-81.

Nuñez, L., N. Barros and I. Barja. 1994. Effect of storage of soil at 4 degrees on the microbial activity studied by microcalorimetry. $\mathrm{J}$. Therm. Anal. Calorim. 41(6): 1379-1383.

Pankhurst, C. E., S. Yu, B. G. Hawke and B. D. Harch. 2001. Capacity of fatty acid profiles and substrate utilization patterns to describe differences in soil microbial communities associated with increased salinity or alkalinity at three locations in South Australia. Biol. Fertil. Soils. 33: 204-217.
Rhoades, J. D., P. J. Shouse, W. J. Alves, N. A. Manteghi and S M. Lesch. 1990. Determining soil-salinity from soil electricalconductivity using different models and estimates. Soil Sci. Soc. Am. J. 54: 46-54.

Rose, D. A., F. Abbas and M. A. Adey. 2006. Limitations in the use of electrical conductivity to monitor the behaviour of soil solution. Aust. J. Soil Res. 44: 695-700.

Shaw, R. J., K. K. Hughes, P. J. Thorburn and A. J. Dowling. 1988. Soil salinity and sodicity. Understanding soils and soil data. In: I. F. Fergus, (Ed),Australian Society of Soil Science Incorporated, Queensland Branch, Brisbane. p. 109.

Shatalin, K., I. Gusarov, E. Avetissova, Y. Shatalina, L. E. McQuade, S. J. Lippard and E. Nudler. 2008. Bacillus anthracis-derived nitric oxide is essential for pathogen virulence and survival in macrophages. Proc. Natl. Acad. Sci. U. S. A. 105(3): 1009-1013.

Shen, W. S., W. H. Zhong, T. Gu, W. Wang, B. Zhang, X. G. Lin and Q. R. Huang. 2010. The effects of mineral fertilizer and organic manure on soil microbial community and diversity. Plant Soil. 326: 511-522.

Shying, H., F. Youzhi, N. Jun, S. Yufang, X. Lihong, F. Yanfang, Y. Yingliang, L. Xiangui and Y. Linzhang. 2016. Different responses of soil microbial metabolic activity to silver and iron oxide nanoparticles. Chemosphere. 147: 195-202.

Shrestha, R. P. 2006. Relating soil electrical conductivity to remote sensing and other soil properties for assessing soil salinity in northeast Thailand. Land. Degrad. Dev. 17(6): 677-689.

Signor, D., C. E. P. Cerri and R. Conant. 2013. $\mathrm{N}_{2} \mathrm{O}$ emissions due to nitrogen fertilizer applications in two regions of sugarcane cultivation in Brazil. Environ. Res. Lett. 8: 15013.

Sikka, R. and B. Kansal. 1995. Effect of fly-ash application on yield and nutrient composition of rice, wheat and on $\mathrm{pH}$ and available nutrient status of soils. Bioresour. Technol. 51(2): 199-203.

Sinsabaugh, R. S. 1994. Enzymic analysis of microbial pattern and process. Biol. Fertil. Soils. 17: 69-74.

Slavich, P. G. and G. H. Petterson. 1993. Estimating the electricalconductivity of saturated paste extracts from 1-5 soil. Water suspensions and Texture. Aust. J. Soil Res. 31: 73-81.

Tabatabai, M. A. and M. Ekenler. 2003. Responses of phosphatases and arylsulfatase in soils to liming and tillage systems. J. Plant Nutr. Soil Sci. 166(3): 281-290.

Tobias, B., W. Lars, B. Gunnar and M. H. Anke. 2016. Differences in substrate use efficiency: Impacts of microbial community composition, land use management, and substrate complexity. Biol. Fertil. Soils. 52: 547-559.

Wang, F., J. Yao, Y. Si, H. Chen, M. Russel, K. Chen, Y. Qian, G. Zaray and E. Bramanti. 2010. Short-time effect of heavy metals upon microbial community activity. J. Hazard. Mater. 173: 510-516.

Wienhold, B. J., M. S. Grigera, R. A. Drijber and K. M. Eskridge. 2006. Soil microbial biomass relationships with organic matter fractions in a Nebraska corn field mapped using apparent electrical conductivity. Soil Sci. Soc. Am. J. 70: 1480-1488.

Wu, J. S., T. D. Ge, S. A. Nie, J. L. Shen, H. A. Xiao, C. L. Tong, D. F. Huang, Y. Hong and K. Iwasaki. 2011. Chemical properties, microbial biomass, and activity differ between soils of organic and conventional horticultural systems under greenhouse and open field management: A case study. J. Soil Sediment. 11: $25-36$

Wu, Y., N. Ding, G. Wang, J. Xu, J. Wu and P. C. Brookes. 2009. Effects of different soil weights, storage times and extraction methods on soil phospholipid fatty acid analyses. Geoderma. 150: 171-178.

Yamano, H. and K. Takahashi. 1986. Computer analysis of kinetic 
data for microbial growth thermograms observed with a batch calorimeter. Agric. Biol. Chem. 50(12): 3157-3164.
Zelles, L. 1997. Phospholipid fatty acid profiles in selected members of soil microbial communities. Chemosphere. 35: 275-294. 